PERSONAL PRACTICE

Neonatal transfusion practice

N A Murray, I A G Roberts

Arch Dis Child Fetal Neonatal Ed 2004;89:F101-F107. doi: 10.1136/adc.2002.019760

Many previously widely accepted neonatal transfusion practices are changing as neonatologists become more aware of the risks to their patients of multiple blood product transfusions. Recent literature and research on neonatal transfusion practice are here reviewed, and practical guidelines and trigger thresholds for blood products commonly used in neonatal medicine are proposed.

See end of article for authors' affiliations ......................

Correspondence to: Dr Murray, Imperial College, Faculty of Medicine, Hammersmith Campus, Hammersmith Hospital, Du Cane Road, London W12 ONN, UK; neil.murray@ic.ac.uk

Accepted 12 July 2003

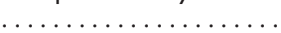

S ick neonates are one of the most heavily transfused groups of patients in modern medicine. However, despite considerable research, most neonatal transfusion practice remains opinion based rather than truly evidence based. Most neonatologists would not prescribe drugs to their patients unless there was a reasonable expectation of benefit. Unfortunately, this rigour does not translate to the prescription of blood products, and as a result there exists a diversity of opinion and practice between different clinicians ${ }^{1}$ and different institutions. $^{2-6}$ Clearly the administration of blood products conveys a finite risk of transmitting potentially serious infections ${ }^{7-9}$ and is not without risk and $\operatorname{cost}^{78}$ It therefore remains a continuing task to define and refine the most clinically appropriate protocols for blood product use in neonates, within the constraints of the available evidence. With these goals in mind this paper reviews recent literature and research on neonatal transfusion practice and proposes practical transfusion guidelines and trigger thresholds for commonly used blood products in neonatal medicine.

\section{RED BLOOD CELLS}

Packed red blood cells (RBCs) are the most common blood product administered to sick neonates. Many previous studies (reviewed in refs ${ }^{10}{ }^{11}$ ) have attempted to define their optimal use in neonates. However, rapidly changing patient populations and characteristics over the last decade, coupled with the introduction of increasingly rigorous transfusion protocols, have reduced the relevance of much of this previous work to modern neonatal practice. Progress in RBC transfusion practice therefore requires a fundamental re-evaluation of its basic aims.

At the most basic level, RBC transfusions are required for two reasons:

- to ensure adequate tissue oxygenation during intensive care periods

- after intensive care, to treat clinically significant symptomatic anaemia
However, neither clinical situation is straightforward to define.

\section{Tissue oxygenation}

Ensuring adequate tissue oxygen delivery Tissue oxygenation is influenced by the concentration and type of haemoglobin $(\mathrm{Hb})$, the concentration of 2,3-diphosphoglycerate within RBCs (both factors affect the Hb-oxygen dissociation curve and thus the oxygen unloading capacity of the blood), and the cardiopulmonary function of the neonate. Apart from $\mathrm{Hb}$ concentration, none of these variables are easily measurable in everyday neonatal practice. In addition, assuming optimised cardiopulmonary function during intensive care, apart from altering $\mathrm{Hb}$ concentration by transfusion (and thereby $\mathrm{Hb}$ type and 2,3-diphosphoglycerate concentration by exchanging $\mathrm{HbF}$ for $\mathrm{HbA}$ RBCs), little can be done to influence these variables on an hour to hour or day to day basis. Thus RBC transfusion remains the only "haematological" treatment option available that has the potential to significantly influence tissue oxygen delivery. However, the question remains how to recognise when a neonate is developing $\mathrm{Hb}$ limited oxygen unloading capacity to the tissues and how to measure this accurately in everyday practice?

Methods of assessing tissue oxygenation Peripheral fractional oxygen extraction (FOE) Direct measurement of tissue oxygenation is not possible. However, surrogate measures have been attempted. Recently, Wardle et al ${ }^{12}$ measured peripheral FOE by near infrared spectroscopy as a surrogate measure of the adequacy of tissue oxygen delivery in 74 neonates $<1500$ g undergoing standard neonatal care. High peripheral FOE $(>0.47)$ was taken as a cut off point suggesting inadequate tissue oxygen delivery and thereby the potential for inadequate tissue oxygenation. This parameter was used as an RBC transfusion trigger in 37 neonates, with the remaining 37 neonates receiving $\mathrm{RBC}$ transfusion guided by a conventional $\mathrm{Hb}$ based protocol. Although there was a trend towards fewer RBC transfusions in the FOE group, this was not significant. However, neonates in the FOE group had lower median $\mathrm{Hb}$ during the study, and time

Abbreviations: $\mathrm{BCSH}$, British Committee for Standards in Haematology; CLD, chronic lung disease of prematurity; DIC, disseminated intravascular coagulation; FFP, fresh frozen plasma; FOE, fractional oxygen extraction; HAS, human albumin solution; $\mathrm{Hb}$, haemoglobin; IVH, intraventricular haemorrhage; NEC, necrotising enterocolitis; NHI, normal human immunoglobulin; RBC, red blood cell; rhEPO, recombinant human erythropoietin 
to first transfusion from study entry was also longer. No difference in major neonatal complications was seen between the two groups, suggesting that no clinical compromise occurred in the neonates in the FOE group. Interestingly, two thirds of transfusions in the FOE group were given because of clinical concerns about low $\mathrm{Hb}$ or symptoms and not because of high FOE. Thus, this method of assessing trigger thresholds for RBC transfusion in preterm neonates deserves further assessment, as sticking closely to high FOE as a transfusion trigger may prove to be a practical method to further reduce RBC transfusions and donor exposure without adversely affecting outcome.

\section{Capillary whole blood lactate}

Lactate concentration has also been assessed as an indicator of tissue oxygenation and/or the need for RBC transfusion. ${ }^{13-}$ ${ }^{16}$ In the intensive care period, lactate concentrations are highly variable, probably reflecting variations in tissue perfusion rather than $\mathrm{Hb}$ limited oxygen unloading capacity to the tissues. Therefore, during intensive care, lactate concentrations are not useful in deciding the need for RBC transfusion. In stable neonates, these concentrations have been shown to decrease after RBC transfusions given for "symptomatic" anaemia. 131516 However, even in stable preterm neonates, lactate concentrations show considerable variation during a 24 hour period,,$^{13}$ and before transfusion they do not correlate with $\mathrm{Hb}$ or packed cell volume. ${ }^{13}$ Thus, peripheral blood lactate concentrations may be useful in the overall assessment of tissue perfusion/oxygenation, but on their own are not a reliable indicator of the need for RBC transfusion.

In summary, with currently available techniques, there is no practical method applicable to everyday neonatal practice that accurately and reproducibly assesses tissue oxygenation.

\section{Trends in clinical practice}

As high quality methods for assessing tissue oxygenation are not available, observational clinical studies of RBC transfusion practice represent the best available evidence to guide future developments. Over the past 15 years, a number of groups have reported on this subject in preterm neonates. Most of these reports show a definite trend towards decreased use of RBC transfusions, even in the most preterm neonates. ${ }^{17-20}$ Importantly, there is no suggestion that this results in an increased need for respiratory support or oxygen therapy or poorer weight gain or increased length of hospital stay. ${ }^{312}$ In addition, there is not an increased incidence of important neonatal complications, such as intraventricular haemorrhage (IVH), necrotising enterocolitis (NEC), chronic lung disease of prematurity (CLD), or sepsis, in preterm neonates managed with a restrictive RBC transfusion policy. ${ }^{3}$

There is less evidence from the converse situation-that is, does maintaining a high $\mathrm{Hb}$ improve outcome in preterm neonates? However, Brooks et al, ${ }^{21}$ who looked at maintaining a packed cell volume $>40 \%$ in preterm neonates in an attempt to reduce retinopathy of prematurity, also reported no reduction in important neonatal complications (IVH, CLD, NEC) as secondary outcome measures. This study only assessed preterm neonates greater than 28 days of age-that is, outside the intensive care period. However, the fact that a low $\mathrm{Hb}$ or packed cell volume by itself (as opposed to clinical concern about the adequacy of tissue oxygenation) is the sole trigger factor for transfusion in many intensive care situations $^{12}{ }^{22}$ suggests that $\mathrm{Hb}$ limited oxygen unloading capacity to the tissues is rare, even during intensive care. In modern neonatal care, this is increasingly the case in the era of antenatal steroids, surfactant, limited acute lung disease, nasal continuous positive airways pressure, and low oxygen requirement.

\section{Guidelines for transfusion of RBCs}

Taking into consideration the available evidence, we use the following RBC transfusion practice in neonates.

\section{Packed RBC product}

The British Committee for Standards in Haematology (BCSH) Transfusion Task Force $^{23}$ recommends the following.

- Components for transfusion in utero or to children under 1 year of age must be prepared from donors who have given at least one donation within the previous two years that was negative for all mandatory microbiological markers.

- Dedicating aliquots from a single donation to allow sequential transfusions from the same donor for neonates/small children who are likely to be repeatedly transfused is considered good practice.

- Components transfused in the first year of life should be cytomegalovirus seronegative (since November 2001 all cellular blood products in the United Kingdom have been leucocyte depleted before hospital issue and are widely regarded as cytomegalovirus safe; nevertheless, in the absence of controlled trials, the BCSH continues to recommend cytomegalovirus negative products for infants).

For a full discussion of recommendations for blood components for use in the newborn, the reader is referred to the BCSH guidelines web site. ${ }^{23}$

\section{Dose (volume) of RBCs}

In preterm neonates the small amount of research available suggests that large volume $(20 \mathrm{ml} / \mathrm{kg}) \mathrm{RBC}$ transfusions lead to larger rises in $\mathrm{Hb}$ and fewer overall transfusions than small volume transfusions $(10 \mathrm{ml} / \mathrm{kg}) .^{24}$ This volume of packed RBCs is well tolerated in the vast majority of preterm neonates. ${ }^{24}$

\section{Triggers for RBC transfusion}

Adhering closely to strict transfusion guidelines reduces transfusion number and donor exposure. ${ }^{18} 25$ This, together with the above data, strongly suggests that the most appropriate RBC transfusion strategy for sick neonates is a large volume restrictive approach directed by strict guidelines using dedicated blood products from a single donation. Table 1 presents suggested RBC transfusion triggers. However, it must be stressed that these trigger levels are only guidelines and some neonates will have no clinical compromise at these $\mathrm{Hb}$ concentrations/packed cell volumes and therefore will not automatically require RBC transfusion.

\section{PLATELETS}

Previous studies suggest that neonatal thrombocytopenia is a risk factor for haemorrhage (particularly IVH), ${ }^{26-30}$ mortality, ${ }^{26273132}$ and adverse neurodevelopmental outcome. ${ }^{29}$ Therefore the sole reason for administering platelet transfusions must be to positively influence these outcomes. However, to date, there has been no neonatal trial that shows reduced haemorrhage or improved outcome in neonates with non-immune mediated thrombocytopenia treated with platelet transfusions. In the only randomised controlled trial addressing this, Andrew et $a l^{33}$ found no benefit in terms of haemorrhage when maintaining a normal platelet count by platelet transfusion in a study of preterm neonates compared with controls with moderate thrombocytopenia (platelets $(50-$ 150) $\left.\times 10^{9} / 1\right)$. 
Table 1 Guidelines for red blood cell (RBC) transfusion thresholds for preterm neonates

\begin{tabular}{|c|c|c|c|c|c|c|}
\hline \multicolumn{3}{|c|}{ Assisted ventilation } & \multicolumn{2}{|l|}{ CPAP } & \multicolumn{2}{|c|}{ Breathing spontaneously } \\
\hline \multicolumn{2}{|l|}{$<28$ days } & \multirow[b]{2}{*}{$\geqslant 28$ days } & & & & \\
\hline $\mathrm{FiO}_{2} \geqslant 0.3$ & $\mathrm{FiO}_{2}<0.3$ & & $<\mathbf{2 8}$ days & $\geqslant 28$ days & $\mathrm{F}_{2} \mathrm{O}_{2}>0.21$ & Well in air \\
\hline $\begin{array}{l}\mathrm{Hb}<12 \mathrm{~g} / \mathrm{dl} \text { or } \\
\mathrm{PCV}<0.40\end{array}$ & $\begin{array}{l}\mathrm{Hb}<11 \mathrm{~g} / \mathrm{dl} \text { or } \\
\mathrm{PCV}<0.35\end{array}$ & $\begin{array}{l}\mathrm{Hb}<10 \mathrm{~g} / \mathrm{dl} \text { or } \\
\mathrm{PCV}<0.30\end{array}$ & $\begin{array}{l}\mathrm{Hb}<10 \mathrm{~g} / \mathrm{dl} \text { or } \\
\mathrm{PCV}<0.30\end{array}$ & $\begin{array}{l}\mathrm{Hb}<8 \mathrm{~g} / \mathrm{dl} \text { or } \\
\mathrm{PCV}<0.25\end{array}$ & $\begin{array}{l}\mathrm{Hb}<8 \mathrm{~g} / \mathrm{dl} \text { or } \\
\mathrm{PCV}<0.25\end{array}$ & $\begin{array}{l}\mathrm{Hb}<7 \mathrm{~g} / \mathrm{dl} \text { or } \\
\mathrm{PCV}<0.20\end{array}$ \\
\hline
\end{tabular}

RBC transfusion may be considered at higher thresholds than the above for neonates with: hypovolaemia (unresponsive to crystalloid infusion); septic shock; necrotising enterocolitis; undergoing/recovering from major surgery.

CPAP, Continuous positive airways pressure; $\mathrm{Hb}$, haemoglobin concentration; PCV, packed cell volume (values derived from capillary samples).

\section{Studies of contemporary platelet transfusion practice in neonates}

Despite the observations described above, sick neonates with thrombocytopenia are often given platelet transfusions. Three recent publications ${ }^{34-36}$ retrospectively document platelet transfusion practice in three separate neonatal intensive care units in the United States, United Kingdom, and Mexico. Despite the geographical differences, several common themes are apparent in these reports.

- Platelet transfusion is common in neonatal intensive care units, occurring in $2-9.4 \%$ of all admissions (more transfusions are given in neonatal intensive care units with a high percentage of intensive care patients and in those units practicing extracorporeal membrane oxygenation).

- Most platelet transfusions are given prophylactically to non-bleeding neonates with platelet counts below $50 \times$ $10^{9} / 1$ and most commonly in those with counts below $30 \times$ $10^{9} / 1$.

- A variety of platelet count triggers for transfusion are used within each unit.

- More than half of neonates given platelet transfusions receive more than one transfusion, with a significant proportion receiving more than four transfusions.

- Thrombocytopenic neonates who receive platelets are up to 10 times more likely to die than neonates who do not receive platelet transfusion (however, the severity of the clinical conditions causing the thrombocytopenia is stressed in all three reports as the major factor leading to mortality, as is the relative rarity of uncontrolled haemorrhage as a direct cause of death in such neonates).

- The uncertainties surrounding platelet transfusions make the exploration of alternative treatments for thrombocytopenia, particularly haemopoietic growth factors (see below), a worthwhile aim.

\section{Developing guidelines for platelet transfusion}

Many platelet transfusion guidelines for the newborn have been proposed. However, we have used these recent clinical reports $^{34-36}$ to develop more realistic guidelines for platelet transfusion in different groups of sick neonates (table 2), by coupling modern practice with what is already known about the incidence and natural history of haemorrhage in sick neonates.

\section{Haemorrhage in sick neonates}

Most neonates who bleed (particularly those with IVH) do so in the first days of life. However, with the exception of perinatal asphyxia, the conditions precipitating most episodes of severe thrombocytopenia-for example, late onset sepsis and NEC-usually develop after the first few days of life. ${ }^{34}$ As highlighted above, patients with these complications rarely have major haemorrhage, even when severely thrombocytopenic. Thus, we believe that prophylactic platelet transfusions are not required for such patients until the platelet count falls below $30 \times 10^{9} / 1$ (table 2 ). Indeed many patients many not be at significant risk of haemorrhage until the platelet count falls much lower. We recommend a higher trigger level $\left(<50 \times 10^{9} / 1\right)$ for patients with the greatest risk of haemorrhage, especially extremely low birth weight neonates $(<1000 \mathrm{~g})$ in the first week of life and neonates with significant clinical instability-for example, fluctuating ventilation requirements or blood pressure (table 2). Platelet transfusions in neonates with platelet counts $>50 \times 10^{9} / 1$ should be reserved for patients with active major bleeding - that is, pulmonary, gastrointestinal, renal-as there is no evidence that higher platelet counts are of any benefit in non-bleeding neonates.

\section{Dose and product}

No trial evidence is currently available on the optimal volume (dose) of platelets to administer or when to administer further transfusions. As with RBCs, larger volumes $(20 \mathrm{ml} /$ $\mathrm{kg}$ ) appear to result in larger and more sustained rises in platelet count compared with smaller volumes $(10 \mathrm{ml} / \mathrm{kg})$ (personal observations). However, a small number of neonates whose thrombocytopenia is the result of severe platelet consumption-that is, in NEC-may not show any appreciable response to even repeated platelet transfusions, and the value of such treatment is questionable given the current paucity of trial evidence. For guidance on appropriate platelet products, the reader is referred to the BCSH web site. $^{23}$

\section{FRESH FROZEN PLASMA}

Traditionally fresh frozen plasma (FFP) has been administered to neonates for a variety of reasons: ${ }^{5}$

- treatment of proven or suspected disseminated intravascular coagulation (DIC)

- prevention of IVH

- volume replacement

- during sepsis (addition of opsonising factors)

- during episodes of thrombocytopenia

- to "correct" prolonged indices of coagulation (unaccompanied by clinical signs of bleeding or other laboratory findings consistent with DIC-for example, thrombocytopenia or RBC fragmentation).

Except for treatment of DIC (which may also require the administration of cryoprecipitate or specific clotting factors), there is no evidence to support the use of FFP in the other clinical situations listed above. ${ }^{37}$

\section{Prevention of IVH}

The large study conducted by the Northern Neonatal Network and reported in $1996^{38}$ clearly shows that prophylactic FFP administered to preterm neonates at birth does not prevent IVH or improve outcome at 2 years of age. 
Table 2 Guidelines for platelet transfusion thresholds for neonates

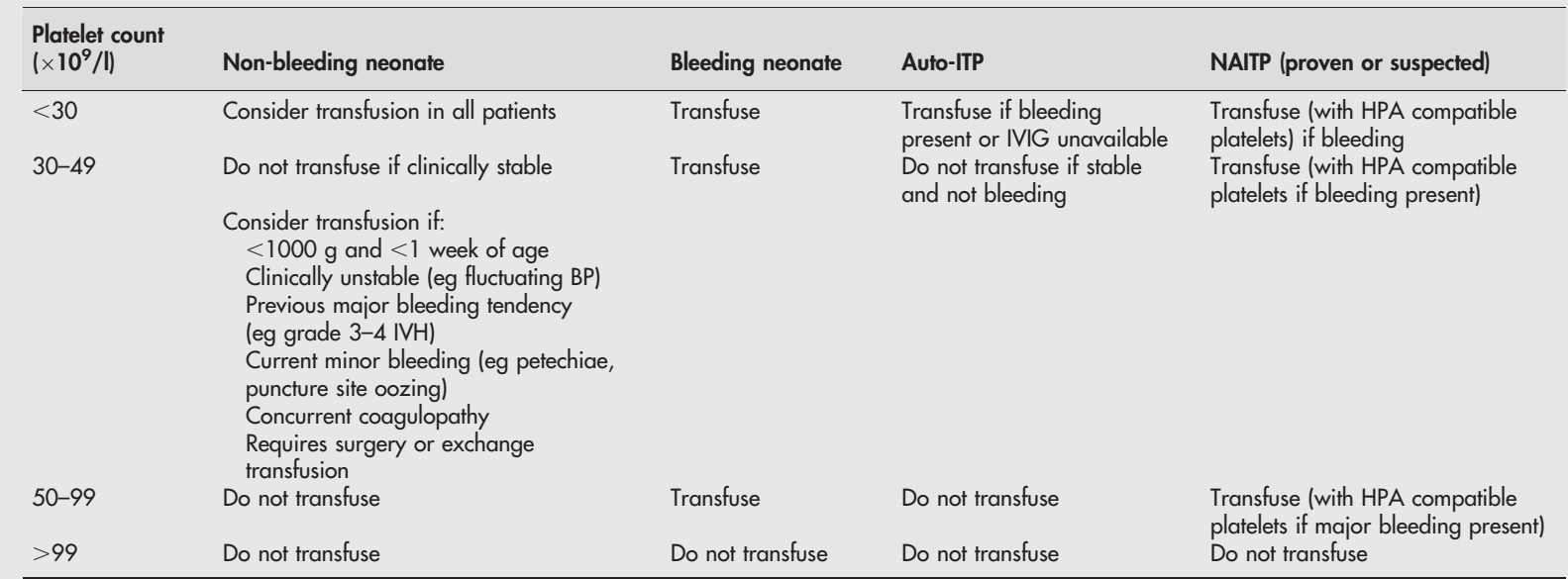

Auto-ITP, Autoimmune thrombocytopenia; NAITP, neonatal alloimmune thrombocytopenia; IVIG, intravenous immunoglobulin; BP, blood pressure; IVH, intravenous haemorrhage; HPA, human platelet antigen.

\section{Volume replacement}

FFP is not superior to other colloid or crystalloid solutions as a volume replacement solution in standard neonatal practice. $^{39} 40$

\section{Sepsis}

Although FFP is often used as an adjuvant therapy during neonatal sepsis, ${ }^{5}$ there have been very few studies that have assessed its efficacy in this clinical situation. Krediet et $a l^{41}$ looked at rises in immunoglobulin G levels and increases in opsonising activity against coagulase negative Staphylococcus in preterm neonates given FFP during clinical episodes of sepsis. They found variable changes in both variables and no influence on outcome.

\section{During neonatal thrombocytopenia}

DIC is present during only $10 \%$ of episodes of neonatal thrombocytopenia. ${ }^{2634}$ Therefore the "blind" administration of FFP to thrombocytopenic neonates is not indicated unless there is good clinical or laboratory evidence of concurrent DIC.

\section{Prolonged indices of coagulation}

Normal values for indices of coagulation have now been established for both term ${ }^{42}$ and preterm neonates. ${ }^{43}$ However, many newborns transiently exhibit abnormal indices of coagulation which are not accompanied by clinical evidence of bleeding and which spontaneously improve over the first days of life. There is no evidence that "correcting" these indices reduces episodes of haemorrhage or improves outcome. ${ }^{30}$ The decision to administer FFP in this situation must be guided by the overall clinical condition of the neonate and not simply by the desire to "treat the numbers".

Dose, guidelines, and product

When used as a source of clotting factors the largest volume appropriate to the cardiovascular status of the neonate should be administered. As above, the only indications for FFP in neonates recommended in the recent $\mathrm{BCSH}$ guidelines and supported by evidence are: ${ }^{23} 44$

- DIC

- vitamin $\mathrm{K}$ dependent bleeding

- inherited deficiencies of coagulation factors.

For guidance on FFP products suitable for neonates, the reader is referred to the $\mathrm{BCSH}$ web site. ${ }^{23}$

\section{HUMAN ALBUMIN SOLUTION}

Human albumin solution (HAS) is used as a primary volume replacement solution for sick newborns. However, HAS is not superior to other colloid or crystalloid solutions as a volume replacement solution in standard neonatal practice. ${ }^{46}$ Concentrated HAS solutions $(20 \%)$ are sometimes administered to hypoalbuminaemic neonates with clinically significant peripheral oedema in an attempt to correct the hypoalbuminaemia, ameliorate the oedema, and hasten clinical improvement. However, there is no convincing evidence to support this practice, ${ }^{47}$ and, as the underlying cause of the hypoalbuminaemia in this situation is almost always inadequate nutritional support, optimising nutrition is the preferred option. As the use of HAS in intensive care patients is associated with excess mortality, ${ }^{48}$ together these data suggest that there is no valid indication for the use of HAS in standard neonatal practice.

\section{NORMAL HUMAN IMMUNOGLOBULIN}

Normal human immunoglobulin (NHI) is standard treatment for both alloimmune and autoimmune neonatal thrombocytopenia and is generally administered to neonates in both clinical situations at platelet counts below $30 \times 10^{9} /$. (Platelet transfusion may also be necessary depending on the clinical condition of the neonate; table 2.) Platelet counts will usually rise promptly after NHI at a dose of $1 \mathrm{~g} / \mathrm{kg}$ on two consecutive days (in single or divided doses). Further courses may be required in refractory or relapsing cases.

There have now been a considerable number of trials assessing the value of NHI as both prophylaxis and adjuvant therapy for neonatal sepsis. A full review of these is beyond the scope of this article. However, Cochrane reviews of both situations suggest that prophylactic NHI is not protective against neonatal sepsis, ${ }^{49}$ but it may be beneficial when given in conjunction with standard treatment for neonatal sepsis. ${ }^{50}$ An international multicentre trial is underway to further address this question. When administered during sepsis the standard recommended dose is $500 \mathrm{mg} / \mathrm{kg}$ as a single dose.

Recent systematic reviews have found that treatment of neonates with alloimmune haemolysis with NHI does reduce the need for exchange transfusion. ${ }^{51}{ }^{52}$ However, the number of studies and infants included is small, and further well designed studies are needed before NHI can be fully recommended for the treatment of neonatal alloimmune haemolysis. ${ }^{51} 52$ 


\section{EXCHANGE TRANSFUSION/DILUTIONAL EXCHANGE}

As severe Rh haemolytic disease of the newborn becomes increasingly rare because of a combination of maternal antiD therapy and intrauterine transfusion of affected fetuses, neonatal exchange transfusion is also becoming an increasingly rare procedure. ${ }^{53}$ When severe haemolytic disease of the newborn is present, exchange transfusion may be used to manage:

- severe anaemia at birth complicated by heart failure (where top up transfusion may exacerbate both fluid overload and heart failure)

- hyperbilirubinaemia

Exchange transfusion is usually carried out by repeatedly exchanging small samples $(5-10 \mathrm{ml} / \mathrm{kg}$ ) of blood through an umbilical venous catheter situated in the inferior vena cava or inferior vena cava/right atrium junction. (The procedure can also be carried out by removing blood from an arterial catheter and replacing blood by continuous infusion into a peripheral or central vein. However, individual units should maintain a standard practice; see below.) When anaemia and heart failure are the most pressing clinical problems, then a single blood volume exchange transfusion $(80-100 \mathrm{ml} / \mathrm{kg}$ ) may be sufficient to ameliorate these problems. However, in the treatment of severe haemolytic disease of the newborn, the aim is to remove both the antibody coated red cells (to reduce further haemolysis and bilirubin production) and the bilirubin already in the circulation. In this situation, a double blood volume exchange transfusion $(160-200 \mathrm{ml} / \mathrm{kg}$ ) is recommended and is estimated to remove $90 \%$ of the initial RBCs and $50 \%$ of the available intravascular bilirubin. ${ }^{23}$ In most cases in the United Kingdom, plasma reduced blood with a packed cell volume of $0.50-0.60$ is used for exchange transfusion to manage both severe anaemia and hyperbilirubinaemia.

In view of the decreasing general experience of the practice of exchange transfusion, all neonatal units must adopt and maintain appropriate written practice guidelines for this procedure. For a fuller discussion of RBC products suitable for exchange transfusion, the reader is referred to the BCSH guidelines for this procedure. ${ }^{23}$

Dilutional exchange transfusion is undertaken to reduce whole blood viscosity in neonates with polycythaemia. Whole blood viscosity rises exponentially when the packed cell volume exceeds $0.65-0.70 .^{54}$ However, even at packed cell volumes $>0.70$, only a minority of neonates exhibit hyperviscosity, ${ }^{55}{ }^{56}$ and, in practice, different neonates appear able to "cope" with different packed cell volumes to a highly variable extent. Performing a dilutional exchange on all neonates with a free flowing venous packed cell volume of $>0.70$ is one method of ensuring treatment for all neonates at risk of hyperviscosity. However, the few follow up studies of the outcome of neonates treated in this way do not show a definite benefit of this strategy. ${ }^{55}$ Indeed it appears that only neonates with proven hyperviscosity are at risk of an adverse neurological outcome. ${ }^{58}$ In practice, there would seem to be two ways to resolve this dilemma: measure whole blood viscosity in all neonates found to be polycythaemic and proceed accordingly, or only perform dilutional exchange transfusion in neonates with a packed cell volume $>0.65-$ 0.70 who have symptoms that suggest a possible adverse outcome (principally neurological symptoms, such as fits, excessive jitteriness, neurological signs, refractory hypoglycaemia). Minor symptoms likely to resolve without risk of adverse outcome-for example, poor peripheral perfusion or borderline hypoglycaemia-can be treated by standard methods until polycythaemia/hyperviscosity resolves spontaneously. We recommend this approach as the most practical for busy maternity/neonatal units.

It should always be remembered in the assessment and treatment of such neonates that umbilical venous catheterisation and dilutional exchange are not without complications. ${ }^{59}$ When considered clinically appropriate, a one third whole blood volume exchange $(80 \mathrm{ml} / \mathrm{kg})$ is usually performed. There is no justification for using other than normal saline as the exchange fluid. ${ }^{60}$

\section{HAEMOPOIETIC GROWTH FACTORS}

In the last decade there has been considerable interest in the potential for haemopoietic growth factors to ameliorate the major haematological problems seen in sick neonates. Again a full review of this subject is beyond the scope of this article. However, it is clear that despite a large amount of research effort, no haemopoietic growth factor has yet found a clear role in standard neonatal practice.

\section{ERYTHROPOIETIN}

There have now been numerous studies assessing the value of recombinant human erythropoietin (rhEPO) administered to preterm neonates to ameliorate anaemia (reviewed in $\left.\operatorname{refs}^{61-63}\right)$. It is quite clear that rhEPO stimulates erythropoiesis, increases indices of RBC production, and reduces RBC transfusion requirement. Although there has been a report of aplastic anaemia developing in adults chronically treated with rhEPO, ${ }^{64}$ this complication has not been seen in neonates. The greatest reduction in transfusion requirement is seen when rhEPO is begun as soon as possible after birth ${ }^{65}$ and at high dose (750-1500 IU/kg/week). Inadequate iron and protein intake limit the effectiveness of rhEPO. ${ }^{66-68}$

Despite these positive findings, the overall reduction in $\mathrm{RBC}$ transfusion requirement in preterm neonates treated with rhEPO is disappointingly small. ${ }^{61-63}$ This is mainly due to the lag time of one to two weeks between beginning treatment and any rise in packed cell volume. As roughly two thirds of all RBC transfusions given to preterm neonates are administered in the first three weeks of life, ${ }^{17-20}$ it is easy to see why even optimally administered rhEPO treatment makes little overall impact on RBC transfusion requirement. rhEPO treatment does significantly increase the number of very low birth weight neonates who do not require any RBC transfusion before discharge, ${ }^{65}$ and this may be seen as a worthwhile clinical outcome. However, treating all such neonates with an rhEPO dose regimen able to achieve this outcome is expensive and labour intensive. Such a strategy also entails giving "unnecessary" treatment to the one third of very low birth weight neonates who would receive no RBC transfusion even without rhEPO therapy. ${ }^{69} 70$ In addition, as RBC transfusion strategies in preterm neonates become increasingly restrictive, it becomes more difficult for rhEPO treatment to achieve a clinically useful reduction in overall transfusion requirement. In conclusion, with the current level of safe RBC products available, rhEPO treatment cannot be recommended to ameliorate anaemia in standard neonatal practice. However, if the supply of safe RBC products declines in the future, rhEPO treatment for preterm neonates may require re-evaluation.

\section{RECOMBINANT HUMAN GRANULOCYTE AND GRANULOCYTE/MONOCYTE STIMULATING FACTORS}

Both these agents increase granulocyte counts in preterm neonates and appear to be free of major side effects. ${ }^{7-75}$ However, the available evidence suggests that neither agent given as prophylaxis, or as adjuvant therapy during neonatal sepsis, significantly improves outcome. ${ }^{71-80}$ Further trials are in progress, but again these agents cannot, as yet, be 
recommended in the treatment of sepsis in standard neonatal practice. $^{76-80}$

\section{THROMBOPOIETIN AND INTERLEUKIN 11}

Both these agents are currently being evaluated in adults and children for their ability to stimulate platelet production and ameliorate thrombocytopenia. ${ }^{81} 82$ However, neither agent has been used in neonates, and it is likely that similar lag problems will be seen with these agents in the treatment of neonatal thrombocytopenia ${ }^{83}$ as outlined above for rhEPO and anaemia.

\section{CONCLUSION}

Many previously widely accepted neonatal transfusion practices are changing as neonatologists become more aware of the risks to their patients of multiple blood product transfusions. Transfusion practices are generally becoming more restrictive, and inappropriate use of blood products is reducing. To continue this improvement neonatologists must:

- apply the same rigour to blood product use in neonates as is seen with drug therapy

- design and conduct appropriate randomised controlled trials of blood product use in neonates to define the best evidence based practice

- construct, adhere closely to, and regularly audit and review guidelines for the administration of all blood products to sick neonates.

\section{Authors' affiliations}

N A Murray, I A G Roberts, Imperial College, Faculty of Medicine,

Hammersmith Campus, Hammersmith Hospital, London W12 ONN, UK

\section{REFERENCES}

1 Calhoun DA, Christensen RD, Edstrom CS, et al. Consistent approaches to procedures and practices in neonatal hematology. Clin Perinatol 2000:27:733-53

2 Bednarek FJ, Weisberger S, Richardson DK, et al. Variations in blood transfusions among newborn intensive care units. SNAP \|I Study Group. J Pediatr 1998;133:601-7.

3 Ringer SA, Richardson DK, Sacher RA, et al. Variations in transfusion practice in neonatal intensive care. Pediatrics 1998;101:194-200.

4 Levy GJ, Strauss RG, Hume H, et al. National survey of neonatal transfusion practices. I. Red blood cell therapy. Pediatrics 1993;91:523-9.

5 Strauss RG, Levy GJ, Sotelo-Avila C, et al. National survey of neonatal transfusion practices. II. Blood component therapy. Pediatrics 1993;91:530-6

6 Maier RF, Metze B, Obladen M. Low degree of regionalization and high transfusion rates in very low birthweight infants: a survey in Germany. J Perinat Med 1998;26:43-8.

7 Busch MP, Kleinman SH, Nemo GJ. Current and emerging infectious risks of blood transfusions. JAMA 2003;289:959-62.

8 Andreu G, Morel P, Forestier F, et al. Hemovigilance network in France: organization and analysis of immediate transfusion incident reports from 1994 to 1998. Transfusion 2002;42:1356-64

9 Quirolo KC. Transfusion medicine for the pediatrician. Pediatr Clin North Am 2002;49:1211-38.

10 Luban NL. Neonatal red blood cell transfusions. Curr Opin Hematol 2002;9:533-6

11 Hume H. Red blood cell transfusions for preterm infants: the role of evidencebased medicine. Semin Perinatol 1997;21:8-19.

12 Wardle SP, Garr R, Yoxall CW, et al. A pilot randomised controlled trial of peripheral fractional oxygen extraction to guide blood transfusions in preterm infants. Arch Dis Child Fetal Neonatal Ed 2002;86:F22-7.

13 Frey B, Losa M. The value of capillary whole blood lactate for blood transfusion requirements in anaemia of prematurity. Intensive Care Med $2001 ; 27: 222-7$.

14 Wardle SP, Weindling AM. Peripheral fractional oxygen extraction and other measures of tissue oxygenation to guide blood transfusions in preterm infants. Semin Perinatol 2001;25:60-4

15 Moller JC, Schwarz U, Schaible TF, et al. Do cardiac output and serum lactate levels indicate blood transfusion requirements in anemia of prematurity? Intensive Care Med 1996;22:472-6.

16 Izraeli S, Ben-Sira L, Harell D, et al. Lactic acid as a predictor for erythrocyte transfusion in healthy preterm infants with anemia of prematurity. J Pediatr $1993 ; 122: 629-31$
17 Beeram MR, Krauss DR, Riggs MW. Red blood cell transfusion practices in very low birth weight infants in 1990s postsurfactant era. J Natl Med Assoc $2001 ; 93: 405-9$.

18 Franz AR, Pohlandt F. Red blood cell transfusions in very and extremely low birthweight infants under restrictive transfusion guidelines: is exogenous erythropoietin necessary? Arch Dis Child Fetal Neonatal Ed 2001;84:F96-100.

19 Maier RF, Sonntag J, Walka MM, et al. Changing practices of red blood cell transfusions in infants with birth weights less than $1000 \mathrm{~g}$. J Pediatr 2000;136:220-4.

20 Widness JA, Seward VJ, Kromer IJ, et al. Changing patterns of red blood cell transfusion in very low birth weight infants. J Pediatr 1996;129:680-7.

21 Brooks SE, Marcus DM, Gillis D, et al. The effect of blood transfusion protocol on retinopathy of prematurity: a prospective, randomized study. Pediatrics 1999; 104:514-18.

22 Corwin HL, Parsonnet KC, Gettinger A. RBC transfusion in the ICU. Is there a reason? Chest 1995;108:767-71.

23 British Committee for Standards in Haematology. www.bcshguidelines.com.

24 Paul DA, Leef KH, Locke RG, et al. Transfusion volume in infants with very low birth weight: a randomized trial of 10 versus $20 \mathrm{ml} / \mathrm{kg}$. J Pediatr Hematol Oncol 2002; 24:43-6.

25 Alagappan A, Shattuck KE, Malloy MH. Impact of transfusion guidelines on neonatal transfusions. J Perinatol 1998;18:92-7.

26 Castle V, Andrew M, Kelton J, et al. Frequency and mechanism of neonatal thrombocytopenia. J Pediatr 1986;108:749-55.

27 Mehta P, Rohitkumar V, Neumann L, et al. Thrombocytopenia in the high risk infant. J Pediatr 1980;97:791-4.

28 Amato M, Fauchere JC, Herman Jr U. Coagulation abnormalities in low birth weight infants with peri-intraventricular hemorrhage. Neuropediatrics 1988; 19:154-7

29 Andrew M, Castle V, Saigal S, et al. Clinical impact of neonatal thrombocytopenia. J Pediatr 1987; 110:457-64.

30 Van De Bor M, Briet E, Van Bel F, et al. Hemostasis and periventricularintraventricular hemorrhage of the newborn. American Journal of Diseases in Children 1986;140:1131-4.

31 Murray NA, Roberts IAG. Circulating megakaryocytes and their progenitors in early thrombocytopenia in preterm neonates. Pediatr Res 1996;40:112-19.

32 Kahn DJ, Richardson DK, Billett HH. Association of thrombocytopenia and delivery method with intraventricular hemorrhage among very-low-birthweight infants. Am J Obstet Gynecol 2002; 186:109-16.

33 Andrew M, Vegh P, Caco C, et al. A randomized, controlled trial of platelet transfusions in thrombocytopenic premature infants. J Pediatr 1993; 123:285-91.

34 Murray NA, Howarth $\sqcup$, McCloy MP, et al. Platelet transfusion in the management of severe thrombocytopenia in neonatal intensive care unit patients. Transfus Med 2002;12:35-41.

35 Garcia MG, Duenas E, Sola MC, et al. Epidemiologic and outcome studies of patients who received platelet transfusions in the neonatal intensive care unit. $J$ Perinatol 2001;21:415-20.

36 Del Vecchio A, Sola MC, Theriaque DW, et al. Platelet transfusions in the neonatal intensive care unit: factors predicting which patients will require multiple transfusions. Transfusion 2001;41:803-8.

37 Contreras M, Ala FA, Greaves M, et al. Guidelines for the use of fresh frozen plasma. British Committee for Standards in Haematology, Working Party of the Blood Transfusion Task Force. Transfus Med 1992:2:57-63.

38 Northern Neonatal Nursing Initiative Trial Group. Randomised trial of prophylactic early fresh-frozen plasma or gelatin or glucose in preterm babies: outcome at 2 years. Lancet 1996;348:229-32.

39 Emery EF, Greenough A, Gamsu HR. Randomised controlled trial of colloid infusions in hypotensive preterm infants. Arch Dis Child 1992;67:1 185-8.

40 Supapannachart S, Siripoonya P, Boonwattanasoontorn W, et al. Neonatal polycythemia: effects of partial exchange transfusion using fresh frozen plasma, Haemaccel and normal saline. J Med Assoc Thai 1999;82(supp 1):S82-6.

41 Krediet TG, Beurskens FJ, van Dijk H, et al. Antibody responses and opsonic activity in sera of preterm neonates with coagulase-negative staphylococcal septicemia and the effect of the administration of fresh frozen plasma. Pediatr Res 1998:43:645-51.

42 Andrew M, Paes B, Milner R, et al. Development of the human coagulation system in the full-term infant. Blood 1987;70:165-72.

43 Andrew M. Paes B, Milner R, et al. Development of the human coagulation system in the healthy premature infant. Blood 1988;72:1651-7.

44 British Committee for Standards in Haematology Haemostasis and Thrombosis Task Force. The investigation and management of neonatal haemostasis and thrombosis. Br J Haematol 2002;119:295-309.

45 Muntean W. Fresh frozen plasma in the pediatric age group and in congenital coagulation factor deficiency. Thromb Res 2002;107(suppl 1):S29.

46 So KW, Fok TF, Ng PC, et al. Randomised controlled trial of colloid or crystalloid in hypotensive preterm infants. Arch Dis Child Fetal Neonatal Ed 1997;76:F43-6.

47 Greenough A, Emery E, Hird MF, et al. Randomised controlled trial of albumin infusion in ill preterm infants. Eur J Pediatr 1993;152:157-9.

48 Alderson $P$, Bunn $F$, Lefebvre $C$, et al. Human albumin solution for resuscitation and volume expansion in critically ill patients. Cochrane Database Syst Rev 2002;(1):CD001208.

49 Ohlsson A, Lacy JB. Intravenous immunoglobulin for preventing infection in preterm and/or low-birth-weight infants. Cochrane Database Syst Rev $2001 ;(2): C D 000361$ 
50 Ohlsson A, Lacy JB. Intravenous immunoglobulin for suspected or subsequently proven infection in neonates. Cochrane Database Syst Rev $2001 ;(2):$ CDO01239.

51 Alcock GS, Liley H. Immunoglobulin infusion for isoimmune haemolytic jaundice in neonates. Cochrane Database Syst Rev 2002;3:CD003313.

52 Gottstein R, Cooke RW. Systematic review of intravenous immunoglobulin in haemolytic disease of the newborn. Arch Dis Child Fetal Neonatal Ed 2003:88:F6-10

53 Funato $M$, Tamai $H$, Shimada $S$. Trends in neonatal exchange transfusions at Yodogawa Christian Hospital. Acta Paediatr Jpn 1997;39:305-8.

54 Upadhyay A, Aggarwal R, Deorari AK, et al. Polycythemia in the newborn. Indian J Pediatr 2002;69:79-82.

55 Rothenberg T. Partial plasma exchange transfusion in polycythaemic neonates. Arch Dis Child 2002;86:60-2.

56 Merchant RH, Phadke SD, Sakhalkar VS, et al. Hematocrit and whole blood viscosity in newborns: analysis of 100 cases. Indian Pediatr 1992;29:555-61.

57 Ratrisawadi V, Plubrukarn R, Trakulchang K, et al. Developmental outcome of infants with neonatal polycythemia. J Med Assoc Thai 1994;77:76-80.

58 Drew JH, Guaran RL, Cichello M, et al. Neonatal whole blood hyperviscosity: the important factor influencing later neurologic function is the viscosity and not the polycythemia. Clin Hemorheol Microcirc 1997; 17:67-72.

59 Supapannachart S, Siripoonya P, Boonwattanasoontorn W, et al. Neonatal polycythemia: effects of partial exchange transfusion using fresh frozen plasma, Haemaccel and normal saline. J Med Assoc Thai 1999;82(suppl 1):S82-6.

60 Wong W, Fok TF, Lee $\mathrm{CH}$, et al. Randomised controlled trial: comparison of colloid or crystalloid for partial exchange transfusion for treatment of neonatal polycythaemia. Arch Dis Child Fetal Neonatal Ed 1997;77:F1 15-18.

61 Ohls RK. Human recombinant erythropoietin in the prevention and treatment of anemia of prematurity. Paediatr Drugs 2002;4:111-21.

62 Strauss RG. Managing the anemia of prematurity: red blood cell transfusions versus recombinant erythropoietin. Transfus Med Rev 2001;15:213-23.

63 Zipursky A. Erythropoietin therapy for premature infants: cost without benefit? Pediatr Res 2000;48:136.

64 Casadevall N, Nataf J, Viron B, et al. Pure red-cell aplasia and antierythropoietin antibodies in patients treated with recombinant erythropoietin. N Engl J Med 2002;346:469-75.

65 Maier RF, Obladen M, Muller-Hansen I, et al. Early treatment with erythropoietin beta ameliorates anemia and reduces transfusion requirements in infants with birth weights below $1000 \mathrm{~g}$. J Pediatr 2002;141:8-15.

66 Rao R, Georgieff MK. Neonatal iron nutrition. Semin Neonatol $2001 ; 6: 425-35$

67 Bechensteen AG, Haga P, Halvorsen S, et al. Effect of low and moderate doses of recombinant human erythropoietin on the haematological response in premature infants on a high protein and iron intake. Eur J Pediatr 1997; 156:56-61.

68 Bechensteen AG, Haga P, Halvorsen S, et al. Erythropoietin, protein, and iron supplementation and the prevention of anaemia of prematurity. Arch Dis Child 1993;69: 19-23.
69 Shannon KM Keith JF 3rd, Mentzer WC et al ecombinant human erythropoietin stimulates erythropoiesis and reduces erythrocyte transfusions in very low birth weight preterm infants. Pediatrics 1995;95:1-8.

70 Maier RF, Obladen M, Scigalla $P$, et al. The effect of epoetin beta (recombinant human erythropoietin) on the need for transfusion in very-lowbirth-weight infants. European Multicentre Erythropoietin Study Group. N Engl J Med 1994;330:1173-8.

71 Ahmad A, Laborada G, Bussel J, et al. Comparison of recombinant granulocyte colony-stimulating factor, recombinant human granulocytemacrophage colony-stimulating factor and placebo for treatment of septic preterm infants. Pediatr Infect Dis J 2002;21:1061-5.

72 Miura E, Procianoy RS, Bittar C, et al. A randomized, double-masked placebo-controlled trial of recombinant granulocyte colony-stimulating factor administration to preterm infants with the clinical diagnosis of early-onset sepsis. Pediatrics 2001;107:30-5.

73 Bedford Russell AR, Emmerson AJ, Wilkinson N, et al. A trial of recombinant human granulocyte colony stimulating factor for the treatment of very low birthweight infants with presumed sepsis and neutropenia. Arch Dis Child Fetal Neonatal Ed 2001;84:F172-6.

74 Carr R, Modi N, Dore CJ, et al. A randomized, controlled trial of prophylactic granulocyte-macrophage colony-stimulating factor in human newborns less than 32 weeks gestation. Pediatrics 1999; 103:796-802.

75 Cairo MS, Agosti J, Ellis R, et al. A randomized, double-blind, placebocontrolled trial of prophylactic recombinant human granulocyte-macrophage colony-stimulating factor to reduce nosocomial infections in very low birth weight neonates. J Pediatr 1999;134:64-70.

76 Baneriea MC, Speer CP. The current role of colony-stimulating factors in prevention and treatment of neonatal sepsis. Semin Neonato 2002;7:335-49.

77 Bernstein HM, Calhoun DA, Christensen RD. Use of myeloid colonystimulating factors in neonates with septicemia. Curr Opin Pediatr 2002;14:91-4.

78 Parravicini E, van de Ven C, Anderson L, et al. Myeloid hematopoietic growth factors and their role in prevention and/or treatment of neonatal sepsis. Transfus Med Rev 2002;16:11-24.

79 Carr R, Modi N. Haemopoietic colony stimulating factors for preterm neonates. Arch Dis Child Fetal Neonatal Ed 1997;76:F128-33.

80 Bernstein HM, Pollock BH, Calhoun DA, et al. Administration of recombinant granulocyte colony-stimulating factor to neonates with septicemia: a metaanalysis. J Pediatr 2001;138:917-20.

81 Kuter DJ, Begley CG. Recombinant human thrombopoietin: basic biology and evaluation of clinical studies. Blood 2002; 100:3457-69.

82 Reynolds CH. Clinical efficacy of rhll-11. Oncology (Huntingt) 2000;14(9 suppl 8):32-40.

83 Sola MC, Christensen RD, Hutson AD, et al. Pharmacokinetics, pharmacodynamics, and safety of administering pegylated recombinant megakaryocyte growth and development factor to newborn rhesus monkeys. Pediatr Res 2000;47:208-14. 